\title{
Structural design and thermal performance simulation of shade roof of double-slope greenhouse for mushroom-vegetable cultivation
}

\author{
Yunfei Ma ${ }^{1,2}$, Xinxing $\mathrm{Li}^{1,3}$, Zetian $\mathrm{Fu}^{1}$, Lingxian Zhang ${ }^{1,3^{*}}$ \\ (1. College of Information and Electrical Engineering, China Agricultural University, Beijing 100083, China; \\ 2. Institute of Yantai, China Agricultural University, Yantai 264670, China; \\ 3. Key Laboratory of Agricultural Informationization Standardization, Ministry of Agriculture and Rural Affairs, Beijing 100083, China)
}

\begin{abstract}
A new type of roof structure was developed for the shade room in a double-slope greenhouse used for mushroom-vegetable planting. A simulation model was developed to evaluate the thermal performance of the new roof with an insulation thickness of $0.12 \mathrm{~m}$ in Beijing, China. The results showed that (1) the indoor air temperature of the shade room with the newly implemented shade roof was $2.7^{\circ} \mathrm{C}-4.9^{\circ} \mathrm{C}$ higher than that of an ordinary shade room during the winter months; (2) The indoor air temperature of the solar room adjacent to the shade room with the new roof was higher than that of the ordinary solar room and the minimum indoor air temperature of the solar room was increased $1.9^{\circ} \mathrm{C}$ at winter night; (3) the indoor temperature of the shade room with the new roof design was $2^{\circ} \mathrm{C}-4^{\circ} \mathrm{C}$ lower than that of the ordinary shade room during the summer months; (4) Under factory production conditions, which were conducted in a controlled environment to promote the annual growth of the edible fungus, the heating energy consumption of the shade room after the implementation of the new roof structure was reduced by $69.3 \%$, the amounted to total energy savings of $61.3 \%$ per year. The new roof structure provided a significant improvement in the thermal environment compared to an ordinary shade room, improved the vegetable growth in the winter, and also significantly reduced the energy consumption and production costs.
\end{abstract}

Keywords: double-slope greenhouse, roof structure design, thermal performance simulation, mushroom-vegetable planting DOI: $10.25165 / j$.jijabe.20191203.4852

Citation: Ma Y F, Li X X, Fu Z T, Zhang L X. Structural design and thermal performance simulation of shade roof of double-slope greenhouse for mushroom-vegetable cultivation. Int J Agric \& Biol Eng, 2019; 12(3): 126-133.

\section{Introduction}

The single-slope greenhouse is an agricultural building type that provides an environment with a suitable amount of heat and humidity for the production of off-season crops by passive absorption of solar radiation ${ }^{[1-3]}$. During the construction of several single-slope greenhouses, a certain amount of space needs to be allocated between adjacent greenhouses to prevent the shading of the rear greenhouse by the front greenhouse. Thus, the land utilization rate of traditional Chinese greenhouses is relatively low $^{[4]}$.

Since the beginning of the century, a new type of double-slope greenhouse, which is commonly referred to as the shaded solar greenhouse, has been predominantly utilized in northern China, including in Ningxia Hui Autonomous Region, Qinghai province, and Inner Mongolia ${ }^{[5]}$. This type of greenhouse is located on the north side of a traditional solar greenhouse and has an equal length, north-facing lighting surface. The two greenhouses share the same wall. Thus, researchers refer to this combined greenhouse as a double-slope greenhouse (Figure 1). In the double-slope greenhouse, the lighting surface that is oriented towards the sun is

Received date: 2018-12-09 Accepted date: 2019-03-10

Biographies: Yunfei Ma, Associate Professor, research interest: facility agriculture engineering, Email: pony521ff@163.com; Xinxing Li, Associate Professor, research interest: agricultural systems engineering, Email: 1xxcau@cau.edu.cn; Zetian Fu, Professor, research interest: agricultural systems engineering, Email: fzt@cau.edu.cn.

*Corresponding author: Lingxian Zhang, Professor, research interest: agricultural systems engineering, P.O.209\#, No.17, Qinghua East Road, Haidian District, Beijing 100083, China. Tel: +86-10-62737653, Email: zhanglx@ cau.edu.cn. known as the solar room, whereas the lighting surface that is oriented away from the sun is known as the shade room ${ }^{[6]}$. The solar room in the double-slope greenhouse is typically used for cultivating vegetables or flowers, whereas the shade room is used for growing fungi, which prefers shade. In this way, the double-slope greenhouse takes advantage of the seasons and provides year-round high-efficient cultivation ${ }^{[7]}$.

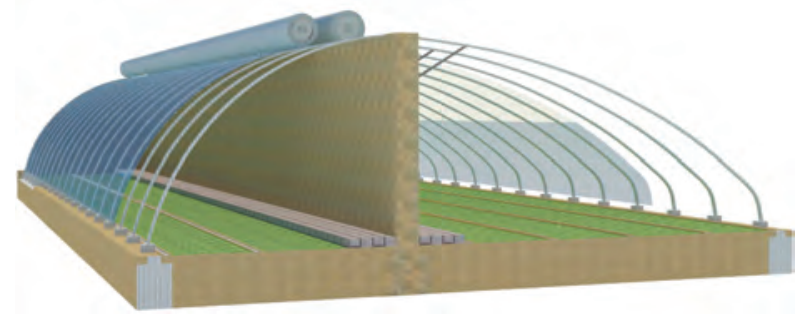

Figure 1 Schematic of a normal double-sloped greenhouse

It has been demonstrated that the implementation of the double-slope greenhouse increases the land use efficiency, decreases the greenhouse construction cost, and improves the energy efficiency. Since this type of greenhouse has already demonstrated great promise with regard to its planting and economic benefits, it is worthy of further study and analysis ${ }^{[8,9]}$. Research on this type of double-slope greenhouse is currently focused on the planning and design of the greenhouse, the testing and analysis of the thermal environment in the greenhouse, and the planting patters suitable for double-slope greenhouses. Su et al. ${ }^{[10]}$ designed a type of double-slope greenhouse and compared it to a typical single-slope solar greenhouse. The results demonstrated that the land utilization rate and the greenhouse area were $35.4 \%$ and $93 \%$ higher respectively for the double-slope greenhouse and the total cost of the greenhouse was $32 \%$ lower. $\mathrm{Liu}^{[11]}$ analyzed 
the temperature inside a double-slope greenhouse and a single-slope solar greenhouse with the same span and examined the differences in the light and humidity conditions of the two greenhouses to evaluate the growing conditions in the greenhouse. $\mathrm{Yu}$ et $\mathrm{al}^{[12]}$ analyzed the annual temperature variation in a double-slope greenhouse and a single-slope solar greenhouse to obtain data to support plant management. $\mathrm{Li}$ and Zhang ${ }^{[13]}$ measured the exothermic status of the shared wall between the shade room and solar room in a double-slope greenhouse. The results indicated that the heat storage capacity of the shared wall increased with an increase in the height of the wall in all seasons. Moreover, studies that have investigated the internal heating environment and efficiency of the planting patterns in double-slope greenhouses have demonstrated that the mushroom-vegetable planting pattern provides the best economic benefits ${ }^{[14-16]}$.

Greenhouse covering materials have a substantial impact on the internal thermal conditions ${ }^{[17]}$. Currently, the roof structure and materials used for the construction of double-slope greenhouses are the same as the materials used for typical solar greenhouses; commonly, a plastic film covers the slanted front roof during the day and a thermal blanket is added at night to maintain the heat inside the greenhouse ${ }^{[18]}$. Thus, there is a lack of research focusing specifically on the roof structure of the shade room and the materials used in the construction of double-slope greenhouses used for mushroom-vegetable planting.

In addition to the shiitake mushroom, common edible fungi such as Agaricus bisporus and straw mushrooms are mostly photophobic edible fungi. These types of fungi do not require light throughout their development or only need light during a certain period in their development ${ }^{[19]}$. Therefore, the thermal blanket of the shade room cannot be rolled up because it is predominantly used to block out the light. Moreover, after being exposed to rain and snow, this can lead to an increase in the thermal conductivity, a decrease in the efficiency, and an increase in the weight of the thermal blanket, resulting in a large amount of energy $\operatorname{loss}^{[20]}$. In addition, since the structural frame and electrical system in the shade room are exposed to a high humidity environment, the frame can rot and short-circuiting of the electrical system can easily occur.

Considering the above-mentioned problems, this study focuses on the roof structure of the shade room in the double-slope greenhouse used for mushroom-vegetable planting. Specifically, this study has the following objectives: (1) to design a new type of shade room roof structure that is suitable for the annual production of edible fungi in the shade room of the double-slope greenhouse; (2) to develop a thermal resistance algorithm to calculate the minimum required insulation thickness for the shaded greenhouse; (3) to create a model and utilize the Energy Plus energy simulation software to simulate the thermal performance and energy consumption of the new shade room surface and that of the double-slope greenhouse; (4) to construct an experimental greenhouse to test the reliability of the simulation results.

\section{Materials and methods}

\subsection{Design factor analysis}

The shade room of the double-slope greenhouse serves as the main cultivation area for mushrooms produced in the mushroom-vegetable planting pattern. The primary conditions for optimal mushroom production are listed below. In particular, the cultivation environment of mushrooms generally requires that the optimal water content of the culture medium is approximately $65 \%$.
The optimal humidity for the growth stage of mycelium is about $75 \%$. The appropriate temperature for the growth of the fruiting body is around $90 \%-95 \%$. The appropriate temperature for mycelial growth is in the range of $20^{\circ} \mathrm{C}-28^{\circ} \mathrm{C}$, whereas the appropriate temperature for growth of the fruiting bodies depends on the mushroom species. The temperature for the growth of low-temperature mushrooms is generally in the range of $15^{\circ} \mathrm{C}$ $22^{\circ} \mathrm{C}$, whereas the temperature for the growth of high-temperature mushrooms is in the range of $22^{\circ} \mathrm{C}-28^{\circ} \mathrm{C}$. Common mushroom mycelia do not need light for growth. Appropriate light supplementation at the budding stage can induce the initiation of the budding stage. The vast majority of mushrooms prefer a slightly acidic ( $\mathrm{pH}$ 5.5-6.5) environment for growth and development ${ }^{[21]}$.

Based on the optimal conditions for fungi growth, the inner surface of the roof of the shade room should be waterproof and corrosion-resistant. The cover layer should be opaque or fluorescent lights can be installed in the shade room to provide supplementary lighting.

Furthermore, mushrooms produced off-season in the shade room can provide an additional revenue stream because there is a low supply of fruits and vegetables in Northern China during that period $^{[22]}$. If off-season or annual factory production is used, it is necessary to provide a suitable temperature environment in the shade room because the inside temperature in greenhouses is the most important influencing factor for crop growth and development and improves the quality and quantity of the produce ${ }^{[23,24]}$.

Due to limited climate control capabilities of solar greenhouses, it is impossible to satisfy the temperature requirements for optimal crop production, especially during cold winter nights ${ }^{[25]}$. Thus, using equipment to control the temperature in the shade room is necessary. Specifically, heat is required during the winter months to guarantee adequate growth and cooling is necessary during the summer months to assure proper mushroom growth. In this production process, the energy cost of the system is directly related to the greenhouse design ${ }^{[26,27]}$. This requires the shade room structure to have good thermal insulation performance to reduce the operating energy consumption of the system.

The schematic in Figure 2 illustrates how energy is exchanged during the day and night in the double-slope greenhouse ${ }^{[28]}$. In this model, the wall and the topsoil are both materials with a high index of thermal inertia which absorb solar energy in the daytime, release heat inside the greenhouse in the nighttime, reduce the heat loss of the greenhouse, and maintain the thermal stability of the greenhouse environment ${ }^{[29,30]}$.

Since the greenhouse cover emits more infrared radiation than it receives from the sky, the inside air temperature of the greenhouse can be lower than the temperature outside of the greenhouse. This effect is evident during clear nights, particularly if no external heating is provided ${ }^{[31]}$. Therefore, any means of mitigating the impact of the external environment on the greenhouse thermal environment should be implemented ${ }^{[32]}$. Thus, it is necessary to design the shade room roof so that it has a high thermal resistance. Furthermore, the shade room roof is rarely able to receive direct sunlight during the winter months; therefore, the heat storage index does not need to be high.

In summary, the roof of the shade room in the double-slope greenhouse used for mushroom-vegetable planting has a multilayer design; the innermost layer is waterproof, which allows for the separation of the steel framework and the damp environment of the shade room; the middle layer has lower thermal conductivity and 
has an insulation layer that provides high thermal resistance, which allows for heat preservation and heat insulation. Additionally, the greenhouse steel structure framework, the wiring, and other equipment are placed inside the insulation layer to avoid damage to the greenhouse structure and short-circuiting of the greenhouse electrical wires. The outer layer is designed as a protective layer that effectively delays the long-term exposure to the atmosphere and thus prevents cracking, aging, and other negative effects. Figure 3 depicts a sectional schematic diagram of the structure of the shade room roof.
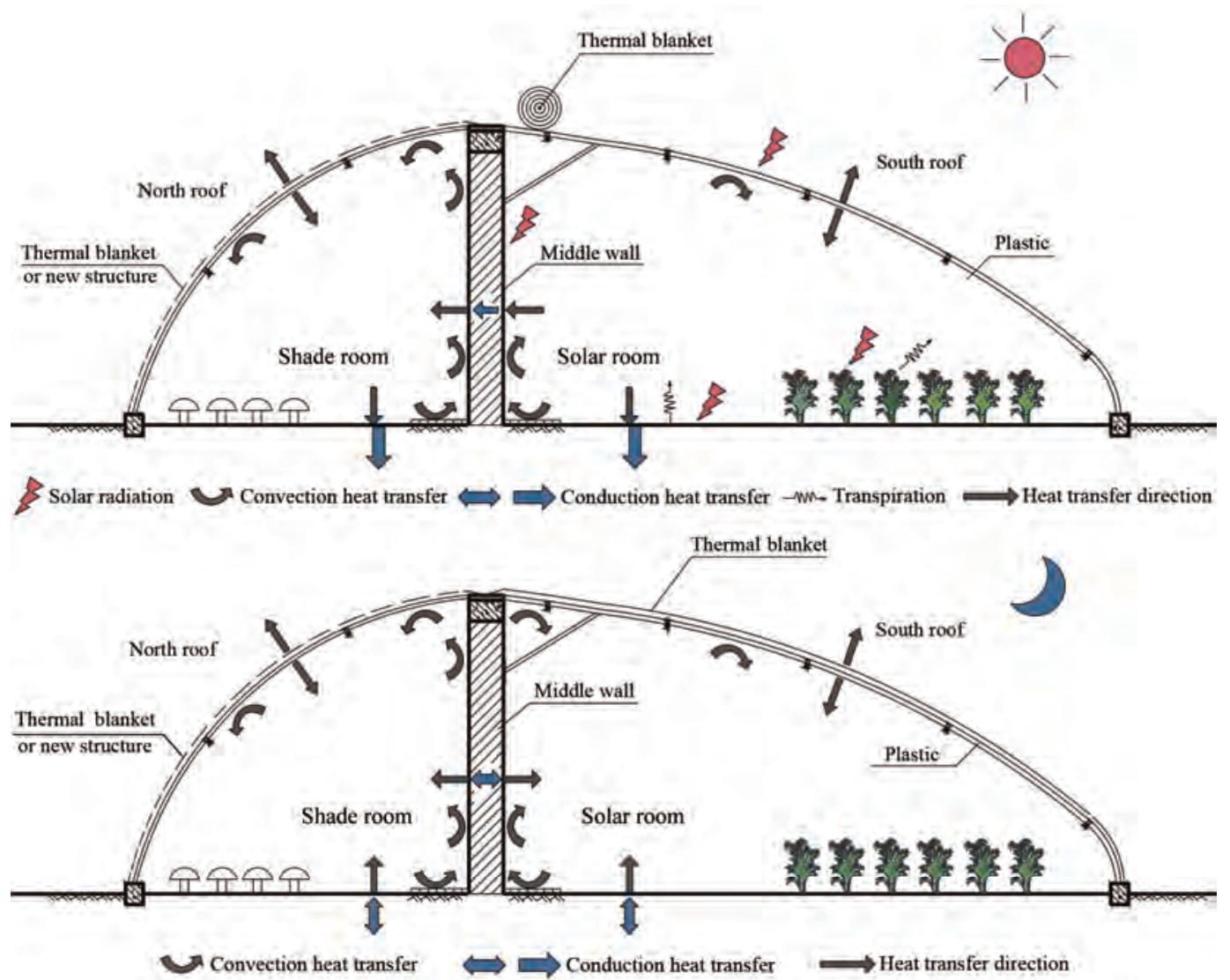

Figure 2 Energy transfer modes in the double-sloped greenhouse during the daytime and nighttime

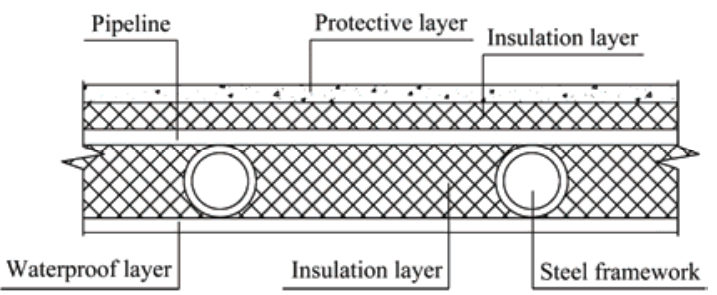

Figure 3 Sectional schematic diagram of the shade room roof structure

\subsection{Material selection for the shade room roof}

\subsubsection{Selection of inner surface materials}

Glass fiber reinforced plastic (GFRP) with a thickness of $0.8 \mathrm{~mm}$ was used for the inner surface of the shade room roof. The ambient temperature should be in the range of $-30^{\circ} \mathrm{C}-120^{\circ} \mathrm{C}$. Furthermore, the material should be lightweight, have high strength, be corrosion resistant, have good insulation performance, and be flexible $^{[33]}$. In the current design, the GFRP board not only acts as a waterproof and moisture-proof surface as the inner layer but it also acts as an insulating agent. Table 1 lists the characteristics of the GFRP board.

\subsubsection{Selection of insulation material}

Since different types of insulation material have different thermal conductivities, dead weight, and water absorption capabilities, the selection of the insulation material is of utmost importance. Common insulation materials include extruded polystyrene boards and rock wool boards. Although these types of insulation materials all have good insulation performance, they are prone to cracking, have low strength, and have a high water absorption rate, respectively ${ }^{[35]}$. For the shade room roof in this study, polyurethane was selected as the insulation material because it has strong adhesion properties, good hydrophobic performance, strong deformation resistance, good freezing resistance, strong flame resistance, and a service life of up to 25 years $^{[36]}$. The performance indicators of the rigid polyurethane are shown in Table 2.

Table 1 Main performance indicators of GFRP boards ${ }^{[34]}$

\begin{tabular}{ccccccc}
\hline $\begin{array}{c}\text { Construction } \\
\text { method }\end{array}$ & $\begin{array}{c}\text { Thickness } \\
/ \mathrm{mm}\end{array}$ & $\begin{array}{c}\text { Density } \\
/ \mathrm{kg} \cdot \mathrm{m}^{-3}\end{array}$ & $\begin{array}{c}\text { Tensile strength } \\
/ \mathrm{MPa}\end{array}$ & $\begin{array}{c}\text { Bending strength } \\
/ \mathrm{MPa}\end{array}$ & $\begin{array}{c}\text { Barker } \\
\text { hardness }\end{array}$ & $\begin{array}{c}\text { Bending } \\
\mathrm{deflection}\end{array}$ \\
\hline Screw fixing & 0.80 & 1500 & 100 & 160 & $\begin{array}{c}\text { Thermal Conductivity } \\
/ \mathrm{W} \cdot(\mathrm{m} \cdot \mathrm{K})^{-1}\end{array}$ \\
\hline
\end{tabular}

Table 2 Main performance indicators of rigid polyurethane ${ }^{[37]}$

\begin{tabular}{|c|c|c|c|c|c|c|c|c|}
\hline $\begin{array}{l}\text { Construction } \\
\text { method }\end{array}$ & $\begin{array}{l}\text { Apparent density } \\
/ \mathrm{kg} \cdot \mathrm{m}^{-3}\end{array}$ & $\begin{array}{l}\text { Thermal Conductivity } \\
\qquad / \mathrm{W} \cdot(\mathrm{m} \cdot \mathrm{K})^{-1}\end{array}$ & $\begin{array}{l}\text { Bond strength } \\
\qquad / \mathrm{MPa}\end{array}$ & $\begin{array}{c}\text { Tensile Strength } \\
\text { /MPa }\end{array}$ & $\begin{array}{l}\text { Elongation } \\
\qquad / \%\end{array}$ & $\begin{array}{c}\text { Water absorption } \\
\text { rate } / \mathrm{N}\end{array}$ & $\begin{array}{c}\text { Dimensional stability } \\
(48 \mathrm{~h}) / \%\end{array}$ & $\begin{array}{l}\text { Flame retardant } \\
\text { performance }\end{array}$ \\
\hline Spraying & $\geq 35$ & $\leq 0.024$ & $\geq 0.15$ & $\geq 0.15$ & $\geq 7$ & $\leq 4$ & $\leq 2.0$ & $\mathrm{E}(\mathrm{B} 2)$ \\
\hline
\end{tabular}




\subsubsection{Selection of the outer surface material}

The outer surface material of the shade room roof consists of a $20 \mathrm{~mm}$ thick layer of 1:2.5 cement mortar and anti-cracking fiber, which forms a protective layer. It is primarily used to protect against weathering and ultraviolet aging and to prolong the shelf life of the insulation layer. Furthermore, if the cement mortar is painted white, the layer reflects a lot of the sunlight during the summer months.

\subsection{Determination of the insulation thickness of the shade room roof}

When the shade room is utilized for year-round factory production or off-season production of mushrooms, the shade room needs to be heated during the winter months and cooled during the summer months to maintain the required growing conditions for the mushrooms. Determining the correct insulation thickness of the shade room thus reduces the energy loss associated with heating and cooling.

The minimum thermal resistance principle can be applied for determining the insulation thickness of the interior surface of the shade room ${ }^{[38]}$. This means that the total thermal resistance of the shade room's roof should not be lower than the calculated minimum heat transfer resistance.

2.3.1 Determination of the minimum heat transfer resistance of the shade room's roof

In Northern China's heating district, the minimum heat transfer resistance of the shade room's roof is determined using Equation $(1)^{[39]}$ :

$$
R_{0, \min }=\frac{\left(t_{i}-t_{e}\right) \eta}{[\Delta t]} R_{i}
$$

where, $t_{i}$ is the temperature of the shade room in the winter; the suitable temperature for the growth of common mushrooms is in the range of $20^{\circ} \mathrm{C}-28^{\circ} \mathrm{C}$; therefore, $22^{\circ} \mathrm{C}$ was selected ${ }^{[40]} . t_{e}$ is the calculated temperature outside of the greenhouse; in the design presented in this study, an index of thermal inertia of $\mathrm{D}<1.5$ was used. This value is based on the method used in Japan and the United States to determine the outdoor temperature, i.e., it uses the average of the cumulative minimum air temperature over a span of 20 years $^{[41,42]}$. $\eta$ is 1.00 , which was used as the temperature correction coefficient; $\Delta t$ is the allowable temperature difference between the indoor air temperature and the inner surface of the enclosure, ${ }^{\circ} \mathrm{C}$. Unlike in residential buildings, in a room for edible mushroom cultivation, condensation is allowed on the inner surface of the room and a value of $7^{\circ} \mathrm{C}$ was used. $R_{i}$ is the heat transfer resistance on the inner surface; a value of 0.11 was used.

2.3.2 Calculation of the thermal resistance $\mathrm{R}$ of the multilayer composition

The thermal resistance $\mathrm{R}$ of the multilayer composition was calculated using Equation $(2)^{[38,39]}$ :

$$
R=R_{1}+R_{2}+\ldots \ldots . R_{n}=\delta_{1} / \lambda_{1}+\delta_{2} / \lambda_{2}+\ldots \ldots+\delta_{n} / \lambda_{n}
$$

where, $R_{1}, R_{2}, \ldots \ldots R_{n}$ is the thermal resistance of each layer; $\delta_{1}$, $\delta_{2} \ldots \ldots \delta_{n}$ is the thickness of each layer; $\lambda_{1}, \lambda_{2} \ldots \ldots \lambda_{n}$ is the thermal coefficient of each layer.

2.3.3 Calculation of the total heat transfer resistance of the shade room's roof

The total heat transfer resistance of the retaining structure was calculated using Equation (3) ${ }^{[38,39]}$ :

$$
R_{0}=R_{i}+R+R_{e}
$$

where, $R_{i}$ is the heat transfer resistance of the inner surface (a value of 0.11 was used); $R_{e}$ is the heat transfer resistance of the external surface (a value of 0.04 was used); $R$ is the thermal resistance of the enclosure.

Equations (1)-(3) are used to calculate the insulation layer thickness of the shade room

\subsection{Energy simulation of the double-slope greenhouse \\ 2.4.1 Simulation software}

In recent years, there has been an abundance of research focusing on the interaction of variables affecting the climate inside greenhouses using computational fluid dynamics $(\mathrm{CFD})^{[43,44]}$. However, it is difficult to use CFD modeling to simulate the conditions in a large greenhouse due to the long computation time required for the calculations; it would be very complex to conduct heating or cooling simulations over long periods ranging from one month to one year ${ }^{[45]}$. Furthermore, CFD modeling also requires technical skill because each model is only developed for a specific greenhouse and cannot be easily applied to other greenhouses ${ }^{[46]}$.

EnergyPlus is a building energy simulation software developed by the US Department of Energy and the Lawrence Berkeley National Laboratory. It not only simulates the heat transfer process with a non-uniform temperature field but also the heating and cooling load of buildings and the annual dynamic energy consumption. EnergyPlus can also output detailed real-time data, such as the average indoor hourly temperature, humidity, and the system's hourly heating and cooling power ${ }^{[47]}$. In recent years, EnergyPlus has also been increasingly used in studies involving the analysis of greenhouse thermal environments and in energy simulation studies ${ }^{[48,49]}$.

\subsubsection{Greenhouse simulation model}

A view of the simulated model sections of the double-slope greenhouses A and B are shown in Figures 4 and 5, respectively. The parameters and descriptions of the model such as the length, span, wall, ground, and the roof structure are shown in Table 3. The thermal performance parameters of various parts of the model greenhouse are shown in Table 4.

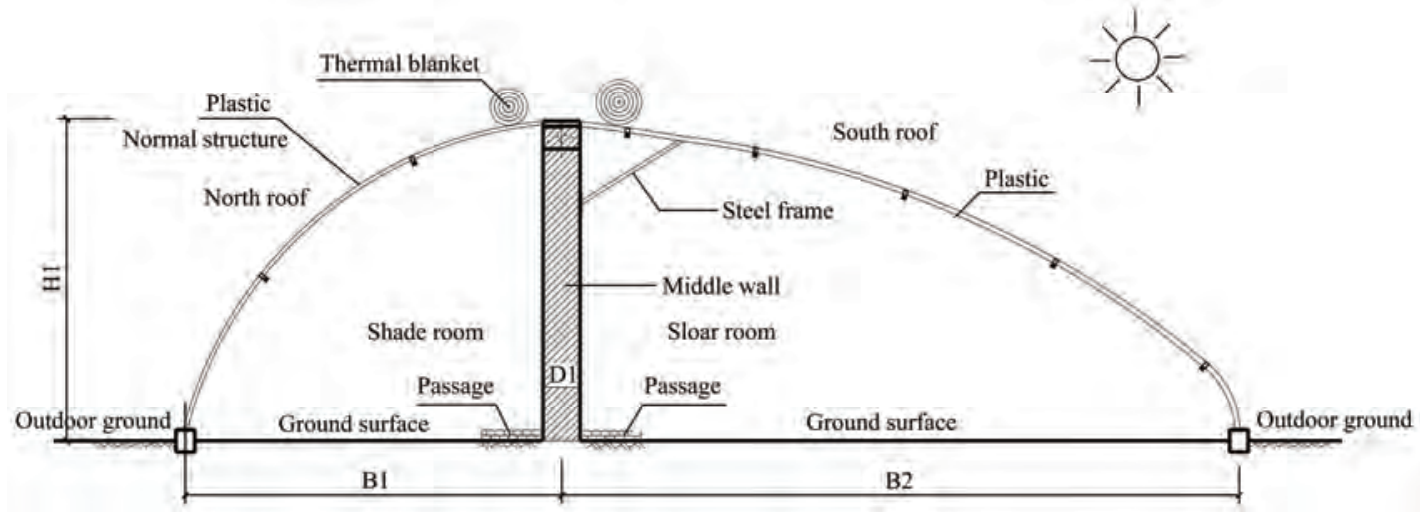

Figure 4 Section view of simulated model greenhouse A 


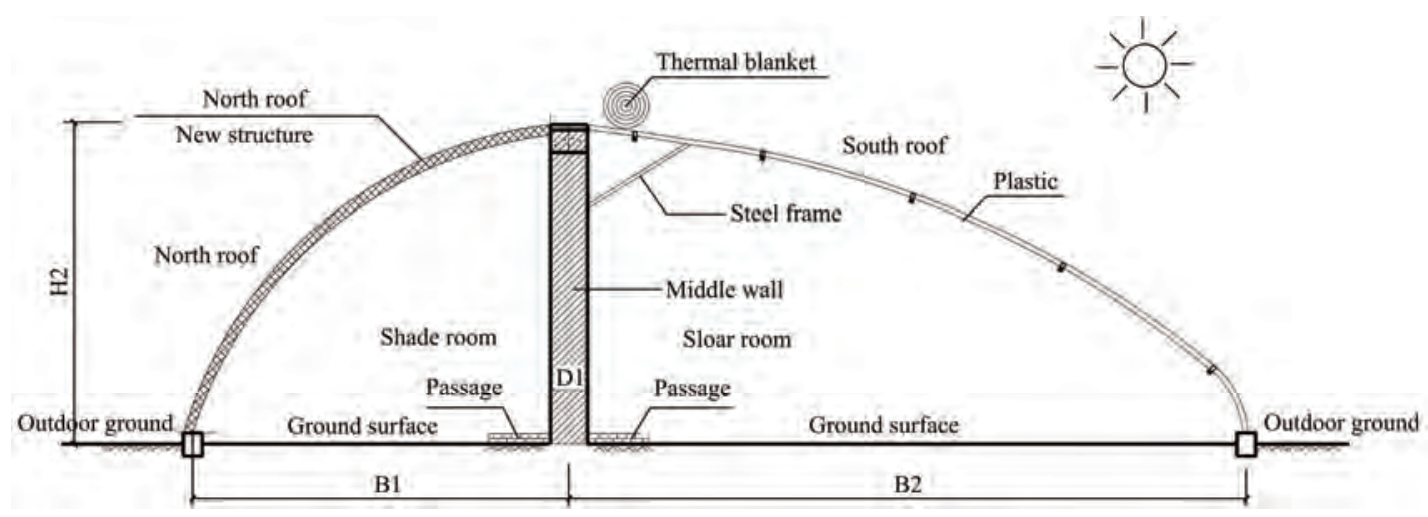

Figure 5 Section view of simulated model greenhouse B

Table 3 Main parameters of the simulated greenhouse model

\begin{tabular}{|c|c|c|}
\hline Component & Parameter & Greenhouse A/B \\
\hline \multirow[t]{5}{*}{ Greenhouse characteristics } & Azimuth angle & South West $5^{\circ}$ \\
\hline & Length/m & 80 \\
\hline & Height $/ \mathrm{m}$ & 4.0 \\
\hline & Width of solar room $/ \mathrm{m}$ & 9.0 \\
\hline & Width of shade room $/ \mathrm{m}$ & 5.0 \\
\hline \multirow[t]{3}{*}{ Middle wall } & Height $/ \mathrm{m}$ & 4.0 \\
\hline & Total thickness $/ \mathrm{m}$ & 0.49 \\
\hline & Material and construction & Slag bricks cemented with cement mortar \\
\hline \multirow[t]{5}{*}{ East and west wall } & Height/m & Shown as Figures 4 and 5 \\
\hline & Total thickness $/ \mathrm{m}$ & 0.56 \\
\hline & Material and construction & Slag brick wall at the outermost layer; the thickness is $0.12 \mathrm{~m}$. \\
\hline & & Polystyrene board in the middle layer; the thickness is $0.07 \mathrm{~m}$. \\
\hline & & Slag brick wall at the innermost layer; the thickness is $0.37 \mathrm{~m}$. \\
\hline North roof (Greenhouse A) & & EVA plastic at the innermost layer; the thickness is $0.0001 \mathrm{~m}$ \\
\hline \multirow[t]{3}{*}{ North roof (Greenhouse B) } & Material and construction & FRP board at the innermost layer; the thickness is $0.0008 \mathrm{~m}$. \\
\hline & & Rigid foamed polyurethane in the middle layer, the thickness is $0.12 \mathrm{~m}$. \\
\hline & & Smearing the surface with 1:2.5 cement mortar plus crack resistant fiber; the thickness is $0.02 \mathrm{~m}$. \\
\hline \multirow[t]{2}{*}{ South roof } & Material and construction & Thermal blanket at the outermost layer, rolled up from 8:30 to $16: 00$ \\
\hline & & EVA plastic at the innermost layer; the thickness is $0.0001 \mathrm{~m}$. \\
\hline \multirow[t]{2}{*}{ Ground } & Ground cover & Shade room ground covered by bricks \\
\hline & & Solar room ground covered by planting soil \\
\hline \multirow[t]{2}{*}{ Location } & Latitude & $39.92^{\circ} \mathrm{N}$ \\
\hline & Longitude & $116.65^{\circ} \mathrm{E}$ \\
\hline \multirow[t]{2}{*}{ Simulating dates } & The winter day & January $22^{\text {nd }}$ \\
\hline & The summer day & July $22^{\text {nd }}$ \\
\hline
\end{tabular}

Table 4 Thermal performance parameters of the simulated greenhouse materials ${ }^{[26]}$

\begin{tabular}{|c|c|c|c|c|c|c|}
\hline Material & $\begin{array}{l}\text { Density } \\
/ \mathrm{kg} \cdot \mathrm{m}^{-3}\end{array}$ & $\begin{array}{l}\text { Specific heat capacity } \\
\qquad / \mathrm{J} \cdot(\mathrm{kg} \cdot \mathrm{K})^{-1}\end{array}$ & $\begin{array}{l}\text { Heat storage coefficient } \\
\qquad / \mathrm{W} \cdot\left(\mathrm{m}^{2} \cdot \mathrm{K}\right)^{-1}\end{array}$ & $\begin{array}{l}\text { Thermal Conductivity } \\
\qquad / \mathrm{W} \cdot(\mathrm{m} \cdot \mathrm{K})^{-1}\end{array}$ & $\begin{array}{l}\text { Absorption } \\
\text { rate }\end{array}$ & Reflectivity \\
\hline Slag brick & 1700 & 1050 & 12.72 & 0.87 & 0.50 & 1.2 \\
\hline EVA film & 950 & 2010 & - & 0.04 & - & 0.15 \\
\hline Polyurethane & 35 & 1380 & 0.54 & 0.024 & - & - \\
\hline FRP board & 1500 & 1260 & 9.26 & 0.40 & - & - \\
\hline Planting soil & 1600 & 1010 & 9.45 & 0.76 & 0.80 & 0.37 \\
\hline
\end{tabular}

Model B has the same construction and dimensions as model A except for the addition of the newly implemented shade room roof. Models $\mathrm{A}$ and $\mathrm{B}$ are equipped with mechanical ventilation openings on the shade room roof and no windows are installed.

2.4.3 Simulation conditions

The simulation consists of two parts:

(1) A simulation of the annual indoor temperature of models A and $\mathrm{B}$ with different constructions of the shade room roof; one winter day and one summer day were selected for analysis and comparison.

(2) A simulation and comparison of the energy consumption in the shade room of models A and B under factory production conditions in a controlled environment for the annual production of edible mushrooms.

The simulated ventilation conditions of the greenhouses were refined based on the actual production management experience and the monthly environmental conditions. In order to simulate the edible mushroom production throughout the year in the shade room, 
the year was divided into six production cycles. In order to minimize the estimated energy consumption and maximizing the return, the production of high-temperature fresh edible straw mushrooms, which are not common in the Northern Chinese market, was scheduled from May $12^{\text {nd }}$ to September $11^{\text {st }}$. Usually, the temperature range of the edible straw mushroom is maintained in the range of $30^{\circ} \mathrm{C}-32^{\circ} \mathrm{C}$. The production of the Agaricus bisporus was scheduled for another time period. The production temperature range of this type of mushroom is generally in the range of $18^{\circ} \mathrm{C}-22^{\circ} \mathrm{C}$.

In addition, the ventilation occurring between the shade room and solar room of the model greenhouses was not considered in the simulation. The meteorological data files used in the simulation were obtained from the "China Meteorological Database for Building Thermal Environment Analysis", which contains the measured data of 270 meteorological stations in China ${ }^{[50]}$. The location of the simulated greenhouse was Beijing.

\section{Results and discussion}

\subsection{Simulated indoor air temperature of the shade room}

The hourly indoor air temperature of the shade room in models $\mathrm{A}$ and $\mathrm{B}$ in the winter and summer are shown in Figure 6.
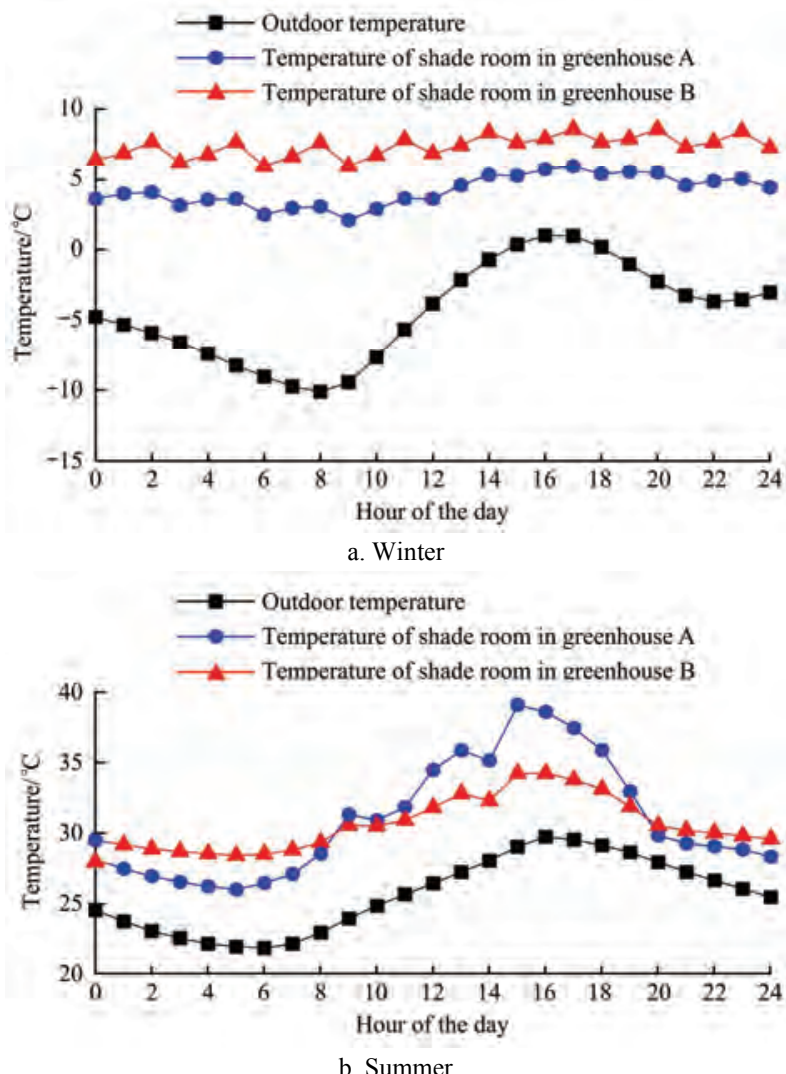

Figure 6 Hourly simulated indoor temperature of the shade room in the winter and summer

Figure 6 shows that the indoor air temperature of the shade room was about $2.7-4.9^{\circ} \mathrm{C}$ higher in model $\mathrm{B}$ than in model $\mathrm{A}$ on January $22^{\text {nd }}$, indicating that the new roof of the shade room effectively improved the thermal environment of the greenhouse during the winter months.

On July $22^{\text {nd }}$, the indoor air temperatures of the shade room were higher than the outdoor air temperatures in models $\mathrm{A}$ and $\mathrm{B}$. In model $\mathrm{A}$, the temperature started to rise around 6:00 with the rising of the sun and reached a maximum of $39.2^{\circ} \mathrm{C}$ around 15:00. After 19:45, the temperature dropped below $30^{\circ} \mathrm{C}$. In model B, the temperature of the shade room from 9:00 to 19:00 was about $2^{\circ} \mathrm{C}-4^{\circ} \mathrm{C}$ lower than that of model $\mathrm{A}$, which was attributed to the high thermal resistance of the newly implemented shade room roof, which effectively prevented the radiant heat from entering the greenhouse during the daylight hours during the summer months.

Figure 6 also shows that the indoor temperature of the shade room was $3^{\circ} \mathrm{C}-6^{\circ} \mathrm{C}$ higher than the outdoor temperature in model $\mathrm{B}$ on July $22^{\text {nd }}$. The temperature in the shade room in model B ranged from $28.4^{\circ} \mathrm{C}$ to $34.4^{\circ} \mathrm{C}$ and remained relatively stable, which was beneficial for the production of high-temperature mushrooms.

\subsection{Simulated indoor air temperature of the solar room}

The hourly indoor air temperatures of the solar room in models $\mathrm{A}$ and $\mathrm{B}$ on winter is shown in Figure 7.

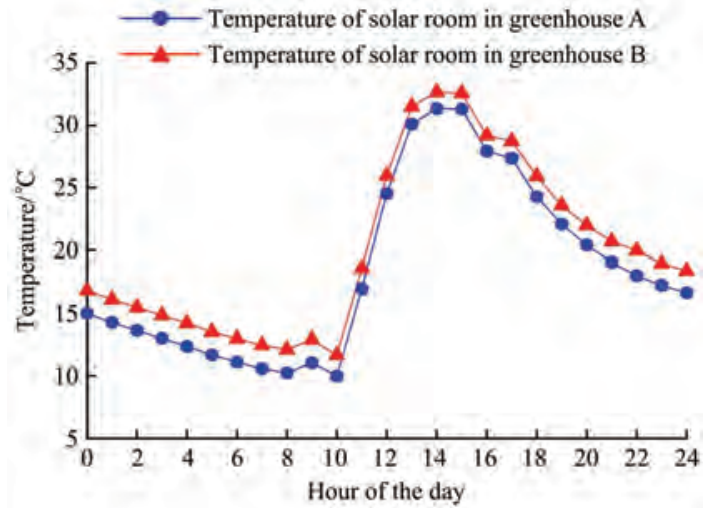

Figure 7 Hourly simulated indoor temperature of the solar room in the winter

The indoor air temperature started to rise around 9:30 after the thermal blanket was retracted and reached a peak temperature around 14:00, subsequently, the temperature decreased. The indoor air temperature of the solar room was higher in model B than in model $\mathrm{A}$ at night. Specifically, the minimum indoor air temperature in the solar room was increased by $1.9^{\circ} \mathrm{C}$, which promoted the growth of vegetables in the winter.

The simulation results showed that the new roof structure not only improved the thermal environment in the shade room but also had a positive impact on the solar room in the double-slope greenhouse.

\subsection{Energy consumption of the shade room}

Figure 8 shows the simulation results of the heating, cooling, energy consumption, and total energy consumption of the model A and $\mathrm{B}$ greenhouses under factory production conditions for the growth of edible mushrooms.

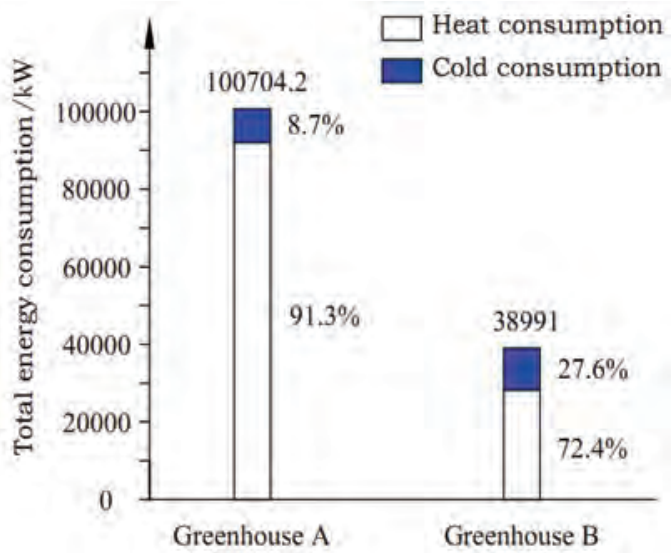

Figure 8 Simulated annual energy consumption of the shade room under factory production conditions 
Under controlled environmental conditions, after the implementation of the new roof in the shade room, the cooling energy consumption were increased by $23.2 \%$ and the heating energy consumption were reduced by $69.3 \%$, respectively. This amounted to a total energy consumption savings of $61.3 \%$ per year, which represents a significant reduction in the energy consumption and the production costs of the greenhouse.

\section{Conclusions}

In the present study, a new construction design was developed for the shade room roof of a double-sided greenhouse used for mushroom-vegetable cultivation. An EnergyPlus simulation model was used to evaluate the thermal performance of the new construction during different seasons.

Based on the results obtained in this study, the following conclusions were drawn. In contrast to an ordinary shade room, the shade room with the new roof construction resulted in an increase in the indoor temperature and an improvement in the thermal environment in the double-slope greenhouse. This, in turn, reduced the occurrence of freezing damage and allowed for the growth of vegetables in the winter. In the summer, the new roof construction stabilized the fluctuations in the indoor temperature, which is conducive to the production of high-temperature mushrooms. In addition, the new roof design significantly reduced the energy consumption and the production costs of the mushroom-vegetable cultivation in the double-slope greenhouse.

\section{Acknowledgements}

This research was made possible through financial support from the Beijing Leafy Vegetables Innovation Team of Modern Agro-industry Technology Research System (BAIC07-2019) and Yantai Science and Technology Development Project (2013ZH083).

\section{Nomenclature}

$R_{i} \quad$ Internal surface resistance of heat transfer, $\mathrm{m}^{2} \cdot \mathrm{K} / \mathrm{W}$

$R \quad$ Thermal resistance of the multilayer composite material, $\mathrm{m}^{2} \cdot \mathrm{K} / \mathrm{W}$

$R_{0} \quad$ Total heat transfer resistance of the envelope, $\mathrm{m}^{2} \cdot \mathrm{K} / \mathrm{W}$

$R e \quad$ External surface resistance of heat transfer, $\mathrm{m}^{2} \cdot \mathrm{K} / \mathrm{W}$

$t_{i} \quad$ Calculated indoor temperature of the shade room in the winter, ${ }^{\circ} \mathrm{C}$

$t_{e} \quad$ Calculated outdoor temperature of the shade room in the winter, ${ }^{\circ} \mathrm{C}$

$\Delta t \quad$ Allowable temperature difference between the indoor air temperature and the inner surface of the enclosure, ${ }^{\circ} \mathrm{C}$

$\delta \quad$ Thickness of material, $\mathrm{m}$

$\lambda \quad$ Thermal conductivity, $\mathrm{W} /(\mathrm{m} \cdot \mathrm{K})$

$\eta \quad$ Correction coefficient of temperature difference

\section{[References]}

[1] Fabrizio E. Energy reduction measures in agricultural greenhouses heating: Envelope, systems and solar energy collection. Energy and Buildings, 2012; 53: 57-63.

[2] Chen C, Li Y, Li N, Wei S, Yang F, Ling H, et al. A computational model to determine the optimal orientation for solar greenhouses located at different latitudes in China. Solar Energy, 2018; 165: 19-26.

[3] Xu J, Li Y, Wang R, Liu W, Zhou P. Experimental performance of evaporative cooling pad systems in greenhouses in humid subtropical climates. Applied Energy, 2015; 138: 291-301.

[4] Cao Y, Jing H, Zhao S, Zou Z, Bao E. Optimization of back roof projection width and northern wall height in Chinese solar greenhouse. Transactions of the CSAE, 2017; 33: 183-189. (in Chinese)

[5] Zhou C. Shade solar greenhouses. Agricultural Engineering Technology, 2011; 4: 48-52. (in Chinese)

[6] Zhou C, Liu C, Wang J. Preliminary study on the environmental conditions of shade solar greenhouses. 2009 proceedings of China Shouguang International Facilities Horticulture High-level Academic Forum, 2009; pp.121-126.

[7] Guo H, Ren P, Li J, Yang P, Han J, Yan C, et al. Study on efficient cultivation mode of shade solar greenhouses in winter. Shandong Agricultural Sciences, 2014; 46: 51-55. (in Chinese)

[8] Wei X, Zhou C, Cao N, Sheng B, Cheng S, Lu S. Evolution of structure and performance of solar greenhouses in China. Journal of Jiangsu Agricultural Sciences, 2012; 28: 855-860. (in Chinese)

[9] Zheng H, Gao Z. Development status and prospects of new double-roof solar greenhouses in Shandong. China vegetables, 2014; 7: 1-3. (in Chinese)

[10] Su D, Wang T, Li M, Meng S. Planning and design of shade solar greenhouses. Journal of Shenyang Agricultural University, 2002; 33: 138-141. (in Chinese)

[11] Liu Y. Analysis of light and temperature environment of different greenhouses in Guanzhong area of Shanxi Province. PhD dissertation. Chongqing: Chongqing Southwest University, 2012, 12. 36p. (in Chinese)

[12] $\mathrm{Yu} \mathrm{Q}$, An X, Wei C, Li X. Analysis of shade solar greenhouses temperature environment. Anhui Agricultural Science, 2016; 44: 37-40. (in Chinese)

[13] Li L, Zhang Y. Combining light with shade solar greenhouses wall of different season shared combustion status. Northern Horticulture, 2010; 15: 80-84. (in Chinese)

[14] Wang G, Liu F, Liu H. Yinyang type solar greenhouse facilities construction and cultivation mode. China Vegetables, 2009; 15: 44-45. (in Chinese)

[15] Li L. Comparative analysis of the environmental characteristics of shade solar greenhouses and the growth of red earth grapes. Master dissertation. Yinchuan: Ningxia University, 2010; 5. 43p. (in Chinese)

[16] Ji Y, Wu Z, Yu P, Liu M. Techniques for co-cultivation of cowpea and oyster mushrooms in shade solar greenhouses. Vegetables, 2014; 2: 46-47. (in Chinese)

[17] Kavga A, Souliotis M, Koumoulos E, Fokaides P, Charitidis A. Environmental and nanomechanical testing of an alternative polymer nanocomposite greenhouse covering material. Solar Energy, 2018; 159: $1-9$.

[18] Dai H, Xue L, Tan C, Lei J. Strawberry cultivation in Chinese solar greenhouse with three thermal walls in northern China. Acta Horticulturae, 2017; 1156: 569-572.

[19] Cotter T. Organic mushroom farming and mycoremediation: Simple to advanced and experimental techniques for indoor and outdoor cultivation. Chelsea Green Publishing, 2014; pp.55-62.

[20] Liu C, Ma C, Wang P, Zhao S, Cheng J, Wang M. Theoretical analysis and experimental verification of heat transfer through thick covering materials of solar greenhouse. Transactions of the CSAE, 2015; 31: 170-176. (in Chinese)

[21] Furlan S A, Virmond L J, Miers D A, Bonatti M, Gern R M M, Jonas R. Mushroom strains able to grow at high temperatures and low $\mathrm{pH}$ values. World Journal of Microbiology and Biotechnology, 1997; 13: 689-692.

[22] Xu H, Zhang Y, Li T, Wang R. Simplified numerical modeling of energy distribution in a Chinese solar greenhouse. Applied Engineering in Agriculture, 2017; 33: 291-304. (in Chinese)

[23] Zuo Z, Mao H, Zhang X, Hu J, Han L, Ni J. Forecast model of greenhouse temperature based on time series method. Transactions of the CSAE, 2010; 11: 173-177. (in Chinese)

[24] Bartzanas T, Tchamitchian M, Kittas C. Influence of the heating method on greenhouse microclimate and energy consumption. Biosystems Engineering, 2005; 91: 487-499.

[25] Wang S, Ma C, Chai L, Kong Y. Equipment in sunlight greenhouse for collecting heat and adjusting temperature. Journal of Agricultural Mechanization Research, 2007; 2: 130-133. (in Chinese)

[26] Mobtaker H G, Ajabshirchi Y, Ranjbar S F, Matloobi M. Simulation of thermal performance of solar greenhouse in north-west of Iran: an experimental validation. Renewable Energy, 2018; 135: 88-97.

[27] Ozkan B, Figen Ceylan R, Kizilay H. Comparison of energy inputs in glasshouse double crop (fall and summer crops) tomato production. Renewable Energy, 2011; 36: 16391644. 
[28] Wang J, Li S, Guo S, Ma C, Wang J, Jin S. Simulation and optimization of solar greenhouses in Northern Jiangsu Province of China. Energy and Buildings, 2014; 78: 143-152.

[29] Li M, Zhou C, Wei X. Thickness determination of heat storage layer of wall in solar greenhouse. Transactions of the CSAE, 2015; 31: 177-183. (in Chinese)

[30] Zhang X, Wang H, Zou Z, Wang S. CFD and weighted entropy based simulation and optimisation of Chinese Solar Greenhouse temperature distribution. Biosystems Engineering, 2016; 142: 12-26.

[31] Piscia D, Montero J I, Baeza E, Bailey B J. A CFD greenhouse night-time condensation model. Biosystems Engineering, 2012; 111: 141-154.

[32] Piscia D, Montero J I, Bailey B, Muñoz P, Oliva A. A new optimisation methodology used to study the effect of cover properties on night-time greenhouse climate. Biosystems Engineering, 2013; 116: 130-143.

[33] Mallick P K. Fiber-reinforced composites: materials, manufacturing, and design. Florida: CRC Press, 2007; 42p.

[34] CAAE, Glass fiber reinforced polyester continuous board (GB/T 14206-2015). Beijing: China Standards Press, 2015. (in Chinese)

[35] Mohammad S A. Performance characteristics and practical applications of common building thermal insulation materials. Building and Environment, 2005; 40: 353-366.

[36] Jelle B P. Traditional state-of-the-art and future thermal building insulation materials and solutions - Properties, requirements and possibilities. Energy and Buildings, 2011; 43: 2549-2563.

[37] CAAE, Rigid polyurethane cellular plastics used in the thermal insulation of building (GB/T 21558-2008). Beijing: China Standards Press, 2008. (in Chinese)

[38] CAAE, Design standards for civil buildings thermal engineering (GB 50176-2016). Beijing: China Construction Industry Press, 2016. (in Chinese)

[39] Ma C, Xiao X. Agricultural biological environmental engineering. Beijing: China Agriculture Press, 2005; 32p. (in Chinese)

[40] Chung K R, Tzeng D. Nutritional requirements of the edible gall-producing fungus Ustilago esculenta. Journal of Biological Science,
2004; 4: 246-252.

[41] Zhang Y, Chen Q. Analysis of heating duration and heating load of multi-span greenhouse in China. Transactions of the CSAE, 2006; 22: 147-152. (in Chinese)

[42] Zhou C J, Ding X M. Outdide temperature for heating load in greenhouse design. Transactions of the CSAE, 2008; 24: 161-165. (in Chinese)

[43] Benni S, Tassinari P, Bonora F, Barbaresi A, Torreggiani D. Efficacy of greenhouse natural ventilation: Enviromental monitoring and CFD simulations of a study case, Energy and Buildings, 2016; 125: 276-286.

[44] Kande D K. A CFD analysis of heat and mass transfer in greenhouses: An introduction. Mathematical Modelling and Applications, 2017; 2: 17-20.

[45] Taki M, Ajabshirchi Y, Rohani A, Matloobi M. Modeling and experimental validation of heat transfer and energy consumption in an innovative greenhouse structure. Information Processing in Agriculture, 2016; 3: 157-174.

[46] Ahamed Md S, Guo H, Tanino K. Development of a thermal model for simulation of supplemental heating requirements in Chinese-style solar greenhouses. Computers and Electronics in Agriculture, 2018; 150: 235-244.

[47] Crawley D B, Lawrie L K, Winkelmann F C, Buhl W F, Huang Y J, Pedersen $\mathrm{C} \mathrm{O}$, et al. EnergyPlus: Creating a new-generation building energy simulation program. Energy and Buildings, 2001; 33: 319-331.

[48] Fabrizio E. Energy reduction measures in agricultural greenhouses heating: Envelope, systems and solar energy collection. Building Energy Saving, 2016; 44: 60-64.

[49] Liu P, Yang H, Guan Y, Chen C, Hu W. Verification and analysis of the solar greenhouse thermal environment simulation by EnergyPlus. Biosystems Engineering, 2016; 142: 12-26.

[50] Meteorological Data Room, Meteorological Information Center, China Meteorological Administration, Department of Building Technology, Tsinghua University. Special Meteorological Data Set for China Building Thermal Environment Analysis, Beijing: China Construction Industry Press, 2005. (in Chinese) 